\title{
CARACTERIZAÇÃO E ENTRAVES DO SISTEMA DE PRODUÇÃOCOM BRACATINGA NA REGIÃO METROPOLITANA DE CURITIBA
}

\author{
Jorge Zbigniew Mazuchowski ${ }^{1}$, Alessandro Camargo Angelo ${ }^{2}$ \\ ${ }^{1}$ Eng. Agrônomo, Dr., Emater, PR, Curitiba, PR, Brasil -jorgemazuchowski@emater.pr.gov.br \\ ${ }^{2}$ Eng. Florestal, Dr., Depto.de Ciências Florestais, UFPR, Curitiba, PR, Brasil - alessandrocangelo@gmail.com \\ Recebido para publicação: 16/06/2010 - Aceito para publicação: 16/03/2012
}

\begin{abstract}
Resumo
O cultivo da bracatinga (Mimosa scabrella Bentham) com finalidade energética existe há mais de 100 anos. Atividade típica da pequena propriedade rural, é cultivada com base na regeneração natural desde a segunda rotação. A madeira é valiosa, com características para uso em várias alternativas industriais, especialmente pela movelaria. Após expansão da área cultivada durante muitos anos, atualmente ocorre redução gradual dessa área plantada. Este estudo buscou identificar as causas de redução dos plantios e outros entraves para o produtor de bracatinga. Em paralelo, procurou definir uma proposta de incremento do manejo dos plantios de bracatinga, enfatizando o uso da madeira pela indústria de móveis. Faz-se análise do produtor, da posse das terras e da disponibilidade de mão de obra, do manejo dos plantios e a remuneração da madeira, aliada ao confronto com as restrições pelos órgãos ambientais, carências organizacionais dos produtores e impedimentos para a atividade estabelecida pela sociedade urbana. Os dados do estudo apontam para uma realidade em que a cadeia produtiva da bracatinga será extinta a curto prazo caso seja mantida a atual intervenção do serviço de fiscalização com rígido enfoque ambientalista, aliado ao desconhecimento da realidade rural na atual ótica da sociedade urbana.

Palavras-chave: Silvicultura da bracatinga; posse da terra; área média; restrições ambientais; organização da produção.
\end{abstract}

\begin{abstract}
Caracterization and impediments for bracatinga production system in Curitiba's Metropolitan Region. Bracatinga (Mimosa scabrella Bentham) cultivation for energetic purposes subsists to more than one hundred years. Typical activity in small rural properties, it is cultivated based on natural regeneration after second rotation. The wood is valuable, and it has characteristics for many alternatives of industrials uses, especially in furniture industry. After many years of expansion of the cultivated area, presently there is a gradual reduction on bracatinga's cultivation area. This research aims to identify causes of such plantings reduction and other impediments to bracatinga's producers, it also aims to define one proposal to bracatinga plantation development focusingits wood use in furniture industry. Therefore, it analyses bracatinga's producers, land ownerships and manual work accessibility, plantation managements and wood remuneration, associated to their confront against environmental public services obstructions, organizational needs of bracatinga's producers and opposition to the rural activity that is established by urban society. The data analyzed points to a reality in which bracatinga's cultivation chain will be extinguished in short time whether it is maintained the actual intervention of inspection services with rigid environmental limitations, associated to the acknowledge of rural reality by the urban society.

Keywords: Bracatinga's silviculture; land ownership; medium space; environmental limitations; production organization.
\end{abstract}

\section{INTRODUÇÃO}

As políticas públicas têm estabelecido prioridades centradas na sociedade urbana, sendo negligentes com o meio rural, por desconsiderarem o contexto vivenciado pelo produtor rural e suas atividades historicamente desenvolvidas. Essa é uma questão nevrálgica da produção de bracatinga.

As primeiras informações sobre o cultivo de bracatinga datam de 1909, constatadas por Romário Martins em Curitiba (PR) e arredores (HOEHNE, 1930). A bracatinga é cultivada segundo dois sistemas 
de manejo tradicionais, baseados na regeneração natural por sementes a partir da segunda rotação (Figura 2). Eles diferenciam-se, basicamente, pela presença ou ausência de culturas agrícolas intercalares no primeiro semestre de cada rotação (CARPANEZZI et al., 2004).

Assim, Mazuchowski et al. (2004) informam que a agrossilvicultura da bracatinga vem sendo desenvolvida há mais de 100 anos, em áreas que ultrapassam 120 mil hectares, concentradas em 60 municípios paranaenses, desde o Vale do Ribeira até União da Vitória, envolvendo mais de 15.000 pequenas propriedades.

A Mimosa scabrella Bentham é árvore perenifólia, da família Leguminosae e da subfamília Mimosaceae, que apresenta duas variedades botânicas -scabrella, com floração no inverno, tendo duas denominações populares diferenciadas pela cor da madeira (bracatinga-branca e bracatinga-vermelha), e aspericarpa (bracatinga-argentina), com floração na primavera-verão, diferenciada pela cor argêntea ou prateada das folhas. Como pioneira, é exigente em sol, de rápido crescimento e ciclo de vida curto (CARVALHO, 1994).

A espécie ocorre em formações densas após a derrubada da floresta seguida de queima dos resíduos. Não se regenera no interior de florestas ou de bracatingais, somente após um distúrbio prévio (CARPANEZZI et al., 2004). O crescimento é maior nos cinco anos iniciais, podendo atingir até $25 \mathrm{~m}$ de altura e $50 \mathrm{~cm}$ de DAP após 8 anos de idade. Após essa idade, é comum entrar em declínio vital, atingindo limite de vida aos 30 anos, individualmente (CARPANEZZI, 1994). Em maciços, apresenta tronco reto e longo; enquanto isolada, apresenta tronco curto e ramificado. A copa é arredondada e seu diâmetro e a forma do tronco variam de acordo com a localização da árvore e do plantio (CARVALHO, 1994; EMPRESA BRASILEIRA DE PESQUISA AGROPECUÁRIA (EMBRAPA), 1988).

Historicamente foi destinada ao mercado de lenha, para queima direta em residências, locomotivas das estradas de ferro e algumas indústrias regionais (cal, açúcar, olarias). Atualmente, a demanda por madeira de bracatinga ampliou-se e também há demanda para finalidade industrial mais nobre - madeira para serraria, laminação e movelaria (Figura 1) e carvão vegetal para exportação (MAZUCHOWSKI; BECKER, 2006).

A madeira roliça pode ser usada em vigamentos e escoras na construção civil. A madeira serrada serve para pisos e assoalhos, móveis e peças de mobiliário (armação de estofados, estrados de cama, laterais e fundos de gavetas, travessas estruturais, cantoneiras), caixotaria, embalagens leves e palets. Como peça torneada, é utilizada externamente pela indústria de móveis, após tratamentos de secagem e usinagem (KLITZKE, 2006).

Especialmente nos municípios da Região Metropolitana de Curitiba, a agrossilvicultura da bracatingas e constitui no principal polo de cultivo, envolvendo 14 municípios e uma área estimada de 50 mil hectares, em sua maioria sem manejo silvicultural (MAZUCHOWSKI, 1990).

Decorrente de convênio entre governo do estado do Paraná, governo da França e FAO, entre 1987 e 1990, diversos estudos e pesquisas relacionados ao sistema agroflorestal da bracatinga foram desenvolvidos, com a implementação do Projeto GCP/BRA/025/FRA - Projeto Bracatinga na Agricultura Familiar da Região Metropolitana de Curitiba, com base no município de Bocaiuva do Sul (MAZUCHOWSKI; LAURENT, 1993).

Posteriormente, de 2003 a 2007, em convênio do Ministério da Integração Nacional com a Secretaria de Estado da Agricultura e do Abastecimento, através da Agência de Desenvolvimento da Mesorregião do Vale do Ribeira/Guaraqueçaba e do Instituto Paranaense de Assistência Técnica e Extensão Rural (EMATER), foi executado o Projeto Unidades Rurais de Desenvolvimento Integrado, com ênfase na produção e fornecimento de madeira de bracatinga com qualidade industrial, especialmente para indústria moveleira. Essa diretriz embasou o fomento para instalação de indústrias locais, definição de parcerias entre produtores e indústrias e formação de mão de obra (MAZUCHOWSKI; BECKER, 2006).

Por outro lado, Mazuchowski e Becker (2006) verificaram que vem ocorrendo na atualidade uma redução da área plantada com bracatinga, em decorrência de quatro fatores básicos:

- Existência de severas restrições ambientais para a atividade de manejo da bracatinga, uma espécie florestal nativa nas propriedades rurais.

- O Instituto Ambiental do Paraná (IAP), com processo de liberação de corte da bracatinga manejada bastante burocratizado e moroso. 
- Substituição parcial das áreas de bracatinga por plantações de pínus e/ou eucalipto, devido à inexistência de restrições ambientais para essas espécies exóticas e incentivos ao setor industrial.

- Intensificação do processo de urbanização microrregional, acarretando inúmeras subdivisões agrárias dos imóveis rurais associados com processos de inventários entre familiares, causando carência de mão de obra e substituição de atividades agrárias.
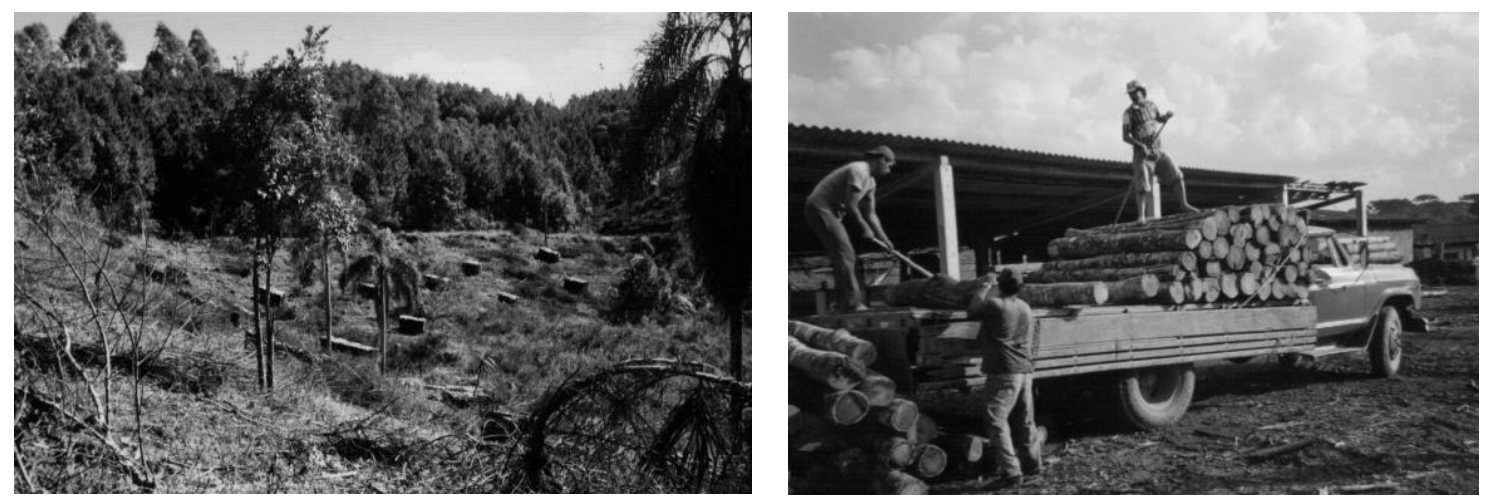

Figura 1. Processo de corte e seleção de toras em bracatingal de propriedade rural para desdobro em serraria, com diâmetros para serrados e peças de movelaria.

Figure 1. Cut processing and logs selection in Mimosa scabrella stands of rural property for cleave wood in sawmill, with diameters to saw up and furniture store.

Destaca-se a comprovação da necessidade de manter parcerias concretas entre o poder público e o setor privado para solução de entraves na produção de bracatinga. A continuidade e a efetivação das soluções para viabilizar o desenvolvimento econômico e social mediante a produção de madeira de qualidade industrial depende do fomento direcionado às demandas do mercado, em bases econômicas estimulantes.

O objetivo do presente estudo foi caracterizar os produtores de bracatinga e identificar parâmetros socioeconômicos do agronegócio da cadeia produtiva da bracatinga, em propriedades integrantes da agricultura familiar na Região Metropolitana de Curitiba. Esse documento considera a hipótese de que, sob as atuais condições, a cadeia produtiva da bracatinga pode simplesmente deixar de existir tal como a conhecemos.

\section{MATERIAL E MÉTODOS}

\section{Localização da área de estudo}

A definição da área-base de estudo embasou-se no critério da concentração de propriedades rurais com cultivo da bracatinga existentes nos municípios, aliada à disponibilidade de informações da cadeia produtiva dessa espécie florestal, para constituição de uma área com oferta de madeira.

Os municípios do Vale do Ribeira no estado do Paraná apresentam densidade populacional média relativamente baixa, com 139,89 habitantes por $\mathrm{km}^{2}$. A economia está atrelada à agricultura familiar, extração mineral e vegetal, com baixa renda familiar e poucas oportunidades de negócios (VALE DO RIBEIRA, 2007).

Para realização deste estudo, considerou-se como área de informações do setor produtivo primário os municípios da Região Metropolitana de Curitiba onde predominam as pequenas propriedades (Tabela 1), com base nos dados de levantamentos do Instituto Brasileiro de Geografia e Estatística (IBGE, 1995), embora os grandes empreendimentos agropecuários e/ou florestais possuam presença marcante como área ocupada. Assim, a coleta dos dados e indicadores das atividades com a bracatinga desenvolveu-se nos municípios de Almirante Tamandaré, Bocaiuva do Sul, Campina Grande do Sul, Campo Magro, Colombo, Curitiba, Rio Branco do Sul e Tunas do Paraná, todos situados entre as latitudes $25^{\circ} 11^{\prime}$ e $25^{\circ} 49^{\prime} \mathrm{S}$ e entre as longitudes $49^{\circ} 05^{\prime}$ e $49^{\circ} 43^{\prime} \mathrm{W}$. Dentre esses municípios, foi selecionado Bocaiuva do Sul. 


\section{Caracterização edafoclimática da área de estudo}

Os terrenos da região estão assentados predominantemente sobre rochas calcárias, sendo comum a presença de dolinas, sumidouros e cavernas, típicas de solos de origem kárstica. A densa rede hidrográfica desloca-se em direção ao Oceano Atlântico pelo Rio Ribeira do Iguape, formando rios encaixados e movimentados, destacando-se como reserva hídrica dos municípios da Região Metropolitana de Curitiba (EMBRAPA, 2007). A topografia é acidentada ou montanhosa, predominando Cambissolos Háplicos alumínicos e distróficos, Argissolo Vermelho distrófico e Latossolo VermelhoAmarelo álico, além de algumas áreas de Cambissolos Húmicos alumínicos e distróficos associados a Afloramentos de Rochas (BHERING et al., 2008).

O clima regional caracteriza-se como tipo $\mathrm{Cfb}$, pela classificação de Köppen, com verões frescos e sem estação seca definida (INSTITUTO AGRONÔMICO DO PARANÁ(IAPAR), 1994). A altitude dos terrenos situa-se acima de 600 metros. Na paisagem fitogeográfica, verifica-se o predomínio de bracatingais, entremeados com florestas de Araucária. As numerosas estradas municipais são sinuosas e de difícil manutenção, em face das carências estruturais das prefeituras municipais (VALE DO RIBEIRA, 2007).

Tabela 1. Representatividade da pequena propriedade rural na estrutura fundiária da Região Metropolitana de Curitiba - IBGE (1995).

Table 1. Representativeness of the small rural properties in the agrarian structure of Curitiba Metropolitan Region - IBGE (1995).

\begin{tabular}{lccccc}
\hline \multirow{2}{*}{ Faixa modular } & \multirow{2}{*}{ Total de imóveis } & \multicolumn{2}{c}{ Área(ha) } & \multicolumn{2}{c}{ Participação (\%) } \\
\cline { 2 - 5 } & & Total & Média & Produtores & Área \\
\hline$<25,0$ & 25.408 & 199.481 & 7,9 & 83,1 & 24,5 \\
25,1 a 100,0 & 4.124 & 186.688 & 45,3 & 13,5 & 23,0 \\
100,1 a $1.000,0$ & 964 & 231.467 & 240,1 & 3,2 & 28,5 \\
$>1.000,1$ & 65 & 195.590 & $3.009,1$ & 0,2 & 24,0 \\
\hline Total & 30.561 & 813.226 & 26,6 & 100,0 & 100,0 \\
\hline
\end{tabular}

Fonte: IBGE (1995).

\section{Levantamento de campo}

Devido à constatação de que a maioria dos cadastros levantados pelos organismos oficiais não permite a obtenção de indicadores de área plantada e do manejo utilizado nos bracatingais das propriedades, tornou-se necessário elaborar um formulário de levantamento específico, englobando as informações requeridas.

\section{a) Elaboração do formulário de levantamento}

Com base nos diferentes tipos de formulários de levantamentos aplicados por diferentes entidades, especialmente Instituto EMATER, IAP, EMBRAPA Florestas e SEAB, além da publicação temática da Câmara Setorial da Cadeia Produtiva da Erva-Mate do Paraná (MAZUCHOWSKI, 2001), foi elaborado um formulário contemplando 12 campos temáticos, relativos à atividade silvicultural com bracatinga na propriedade rural.

O questionário elaborado, do tipo semiestruturado, permitiu o registro dos comentários efetuados pelos entrevistados, embora as perguntas apresentassem alternativas de respostas pré-codificadas. Em decorrência, obtiveram-se informações relativas a pontos de caráter estratégico na cultura da bracatinga.

\section{b) Cronograma de visitas às propriedades}

Os levantamentos foram realizados no decorrer de um ano, entre 2005 e 2006, em face da execução de outras atividades paralelas pelos membros da equipe de campo. Para sua execução, definiu-se que a amostragem seria realizada em todas as 257 propriedades rurais com bracatinga previamente identificadas.

Em decorrência, para os levantamentos programados em cada uma das comunidades rurais identificadas, foi definido um cronograma de visitas específico, com apoio das lideranças locais, visando estabelecer a época de realização dos levantamentos cadastrais correspondentes a cada imóvel e de seus proprietários, simultaneamente aos dados socioeconômicos dessas comunidades. 
A obtenção dos dados e a visita ao bracatingal de cada propriedade consumiram um tempo médio de meio dia por levantamento de cada imóvel, resultando em 130 dias-homem empregados para a coleta dos dados.

\section{c) Critérios para agrupamento de comunidades rurais}

Em função da existência de inúmeros grupos comunitários, adotou-se o critério de agrupamento das comunidades rurais com agrossilvicultura da bracatinga. Assim, inicialmente buscou-se uma classificação não hierarquizada das propriedades rurais, a qual foi inviabilizada por não permitir o uso imediato dos resultados obtidos por grupos de propriedades típicas, em face do elevado número de grupos identificados (19) e da forte variação interna registrada nos fatores área e renda bruta total. A solução foi estabelecer nova tipologia, baseada em análise fatorial e classificação hierarquizadados dados originais.

Para efeito do zoneamento, utilizou-se o método de análise multivariável simples, conhecido como matrizes ordenáveis, baseado no ordenamento progressivo por linhas e colunas da matriz inicial (indivíduos frente variáveis), até a obtenção de grupos homogêneos. Esse processo metodológico já havia sido empregado em 1988, pelo Projeto FAO-GCP/BRA/025/FRA (LAURENT, 1990), visando obtenção do agrupamento das comunidades produtoras de bracatinga. As zonas homogêneas permitem a identificação de propriedades típicas e a definição das prioridades para as diversas atividades de fomento do sistema bracatinga. Foram selecionadas 15 variáveis classificatórias, com elevada variação entre os grupos: área total da propriedade, área de bracatinga, área de milho-feijão, área de pastagens, área de pousio, índice de presença de olericultura/fruticultura, número de bovinos de leite e de corte, número de suínos, mão de obra contratada, trabalho fora da propriedade, renda bruta total e por hectare, índice de declividade das terras acima e abaixo de $20 \%$.

Trata-se de um ordenamento manual dos dados das propriedades e comunidades rurais, com cruzamento de informações em linhas e colunas, em que os dados foram ordenados em 4 modalidades de enquadramento por variável, embasados em quartis de distribuição, numa planilha de tipificação das propriedades e comunidades rurais. As informações levantadas nos 257 questionários de imóveis rurais foram agrupadas e processadas, para estabelecer padrões ou parâmetros dos produtores de bracatinga, em planilhas específicas, destacando-se: caracterização dos produtores, situação do passivo AMBIENTAL; área do SISLEG definida no imóvel e sua averbação na escritura do imóvel; tipo de manejo desenvolvido no bracatingal; caracterização do bracatingal; uso da mão de obra na propriedade; formação de renda média da propriedade; problemas com legislação, infraestrutura e tecnologia com bracatinga; e migração dos filhos.

\section{RESULTADOS E DISCUSSÃO}

Nos resultados, a caracterização do produtor de bracatinga, sua posse da terra e disponibilidade de mão de obra, manejo dos bracatingais e remuneração pela madeira são aspectos fundamentais no confronto com as restrições ambientais, carências organizacionais e impedimentos impostos pela sociedade urbana.

Desde 1970, as cidades integrantes da Região Metropolitana de Curitiba têm tido forte crescimento populacional, em grande parte ligado ao fenômeno de êxodo rural e desenvolvimento industrial, observado por Laurent (1990). Nesse contexto, a redução da densidade da população rural nos municípios com bracatinga tornou-se uma realidade socioeconômica, associada à escassez de mão de obra e baixos níveis de tecnologia silvicultural, pois são praticamente inexistentes políticas públicas para manutenção da população rural e/ou geração de alternativas econômicas, tornando muito difícil evitar a polarização exercida pela cidade de Curitiba.

\section{Identificação dos produtores de bracatinga}

Os levantamentos de dados cadastrais existentes nos arquivos do Instituto EMATER, nos municípios de Bocaiuva do Sul, Rio Branco do Sul, Campina Grande do Sul e Tunas do Paraná, forneceram informações referentes aos produtores rurais e sua localização geográfica por comunidade e ao dimensionamento fundiário dos imóveis rurais e dos bracatingais existentes nas propriedades.

Contudo, as informações disponibilizadas não apresentaram todos os indicadores demandados, especialmente relativos a tempo de permanência na terra, pessoas residentes e em atividade na propriedade, 
renda familiar média e individual, principais atividades, dimensionamento da área e faixa etária dos bracatingais. No levantamento realizado em campo, obtiveram-se os dados complementares específicos.

\section{Regularização da posse da terra}

Verificou-se que $91 \%$ dos produtores de bracatinga são proprietários de seus imóveis e apenas 9\% são posseiros ou arrendatários das terras. Dentre os produtores posseiros, majoritariamente $70 \%$ deles apresentam idade superior a 50 anos de idade, fator dificultador ao processo de manejo dos bracatingais.

No tocante ao documento escritural de posse das terras do imóvel rural, observou-se que, embora todos sejam proprietários legítimos, pelo menos $50 \%$ deles ainda não possuem o registro definitivo da escritura do imóvel emitido pelo Cartório de Registro de Imóveis da Comarca. Tal fato é decorrente da falta de regularização fundiária das propriedades rurais, atribuição que originalmente era efetuada pelo Instituto Ambiental do Paraná (IAP) e atualmente passou ao Instituto de Terras, Cartografia e Geografia (ITCG), ambos vinculados à Secretaria de Estado do Meio Ambiente e Recursos Hídricos (SEMA). Essa situação impede que os produtores de bracatinga tenham acesso ao crédito bancário visando o incremento de atividades em suas propriedades. Historicamente, o estado não tem solucionado o problema, conforme depoimentos dos produtores de bracatinga, apesar da criação de um órgão especializado, sugerindo a necessidade de se efetuar uma força-tarefa para encaminhamento legal no curto prazo.

No aspecto de regularização das áreas de reserva legal e áreas de preservação permanente nas propriedades rurais, efetuada mediante registro na escritura do imóvel rural correspondente e especialmente junto ao IAP, no Sistema de Manutenção, Recuperação e Proteção da Reserva Florestal Legal e Áreas de Preservação Permanente (SISLEG), verificou-se que apenas $15 \%$ dos entrevistados tinham realizado o registro e averbação na escritura. Embora todos os proprietários tenham clareza sobre a localização e dimensionamento das áreas correspondentes, verificou-se que a causa básica do baixo índice de regularização encontra-se no relativo custo elevado da elaboração dos levantamentos topográficos e a confecção dos documentos, intimamente ligados à indisponibilidade financeira dos produtores de bracatinga.

\section{Oferta de mão de obra rural}

Nas propriedades rurais com bracatinga, verificou-se elevada escassez de mão de obra (Tabela 2), embora os indicadores primários possam apresentar valores relativos favoráveis, os quais devem ser cotejados com a idade média dos produtores e a área total de bracatinga nas propriedades rurais correspondentes.

Do total de propriedades com bracatinga, em $73 \%$, ou seja, em 188 delas, verificou-se a disponibilidade de 278 pessoas como mão de obra familiar, resultando num fator médio de 1,4 pessoa por imóvel, índice baixo para atender as necessidades da maioria das propriedades rurais. Por sua vez, em 47\% do total de imóveis, ou seja, em 120 propriedades rurais, verificou-se que ocorre a contratação de mão de obra para serviços temporários, especialmente na colheita da madeira (serviços de limpeza da área, corte das árvores, empilhamento e transporte interno da madeira, entre outros serviços).

Tabela 2. Caracterização da disponibilidade de mão de obra nos imóveis rurais com bracatinga frente à mão de obra contratada - 2007.

Table 2. Characterization of the rural labor available in the Mimosa scabrella properties in relation toregistered rural labor - 2007.

\begin{tabular}{llcc}
\hline & \multicolumn{2}{c}{ Imóveis rurais(n $\left.{ }^{\mathbf{0}}\right)$} & \multirow{2}{*}{$\begin{array}{c}\text { Disponibilidade de } \\
\text { mão de obra familiar(no }\end{array}$} \\
\cline { 2 - 3 } Total do estudo & \multicolumn{2}{c}{ Mão-de-obra disponibilizada } & \\
\cline { 2 - 3 } & Familiar & Contratada & 278 \\
\hline 257 & $188(73 \%)$ & $120(47 \%)$ & 278 \\
\hline
\end{tabular}

\section{Zoneamento agroeconômico das comunidades rurais}

A aplicação da metodologia de matrizes ordenáveis, visando uma atualização dos dados da área de estudo, permitiu inferir algumas alterações nos indicadores componentes dos agrupamentos de comunidades rurais distribuídos em quatro zonas agroeconômicas (Figura 2). 


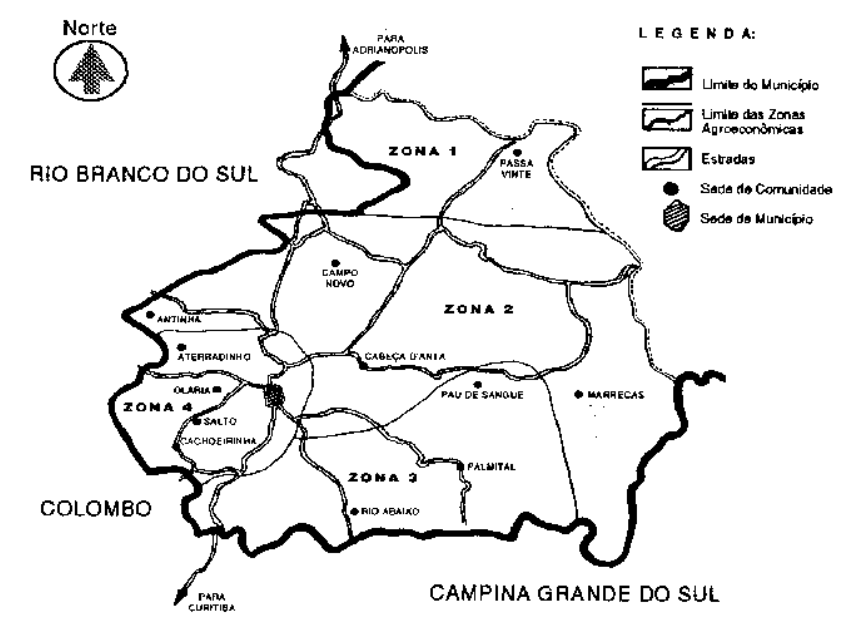

Figura2. Zoneamento agroeconômico das comunidades rurais do levantamento da bracatinga.

Figure 2. Agronometrical zoning of the rural communities for Mimosa scabrella surveys.

As características das zonas agroeconômicas são analisadas na tabela 3, com diferenciações de uso das terras e disponibilidade de trabalho nas propriedades rurais por grupo de comunidades referentes ao tamanho médio dos imóveis rurais, intensidade de manejo de bracatinga e usos da terra, além da mão de obra disponível.

A legenda empregada permite interpretar os quatro quartis de mensuração existentes em cada agrupamento de comunidades rurais e os critérios específicos empregados. Destaca-se a correlação entre tamanho médio das áreas de plantio de bracatinga e o tamanho médio das propriedades, frente à mão de obra disponível.

O tópico "suínos" identifica animais que não são de típica criação com utilização de tecnologia, mas sim de criação tradicional para uso familiar, em que os excedentes são comercializados na sede municipal, na maioria dos casos. O tópico "bovinos" integra bovinos para produção de leite e para carne. A produção de leite destina-se basicamente ao consumo familiar, com excedentes sendo destinados para produção de queijo artesanal e de manteiga, com pouca destinação comercial. Os bovinos de corte apresentam majoritariamente destino comercial, apesar dos baixos níveis de tecnologia empregada. A ocorrência de aves é comum nas comunidades, embora não referida, uma vez que o destino é consumo próprio, sejam ovos ou principalmente carne.

Como principais características de cada zona agroeconômica, destacam-se:

ZONA 1 - comunidades de Tigre, Ouro Fino, Passa Vinte, João XXIII e Tunas, todas integrantes de Tunas do Paraná, município desmembrado de Bocaiuva do Sul.

Trata-se de área marcada pelo contraste entre propriedades de latifúndio e minifúndio, onde as antigas áreas de bracatinga foram substituídas por plantios de pínus, em sua maioria. As pastagens têm presença marcante devido à escassez de mão de obra. As fortes declividades superam 100\%, representando o principal fator limitante. Fora das grandes propriedades de gado de corte e plantio de pínus, a produção agrícola gira em torno da autossubsistência, com o trabalho assalariado representando a maior fonte de renda.

ZONA 2 - comunidades de Antinha, Campo Novo, Cabeça D'Anta e Marrecas.

As propriedades são pequenas, com área inferior a 15 ha, especialmente na Antinha, com produção relativamente diversificada. A área trabalhada é total, pouco recorrendo a arrendamento de novas áreas. Predomina o sistema clássico de milho-feijão e suínos, com alguns produtores de bovinos e plantios de eucalipto e/ou pínus. Trata-se de região com a menor fertilidade natural da área. A olericultura é inexpressiva, com predomínio de pastagens e capoeiras. A bracatinga vem associada na paisagem, com potencial de expansão. 
ZONA 3 - comunidades de Rio Abaixo, Palmital, Pau de Sangue e Bom Retiro.

Constituída por propriedades médias, apresenta duas orientações de produção marcantes, tendo mais da metade dos produtores com produção de bracatinga, em regime de especialização silvicultural, enquanto os demais desenvolvem a produção de carne bovina. Também o cultivo de pínus tem presença marcante. Os terrenos apresentam declividades acentuadas, entre 30 e $60 \%$.

Tabela 3. Caracterização das diferenciações de uso das terras e de disponibilidade de trabalho nas propriedades, por comunidades rurais.

Table 3. Characterization of land uses differentiation and work availability in properties in the rural communities.

\begin{tabular}{|c|c|c|c|c|c|c|c|c|}
\hline \multirow{3}{*}{$\begin{array}{l}\text { Zona } \\
\text { agroeco- } \\
\text { nômica }\end{array}$} & \multirow{3}{*}{$\begin{array}{l}\text { Comunidades } \\
\text { básicas }\end{array}$} & \multirow{3}{*}{$\begin{array}{c}\text { Tamanho } \\
\text { médio do } \\
\text { imóvel(1) }\end{array}$} & \multicolumn{5}{|c|}{ Intensidade de uso das terras nas propriedades (2) } & \multirow{3}{*}{$\begin{array}{c}\text { Trabalho } \\
\text { disponível } \\
\text { (3) }\end{array}$} \\
\hline & & & \multicolumn{2}{|c|}{ Bracatinga } & \multirow[b]{2}{*}{ Olericultura } & \multirow[b]{2}{*}{ Suínos } & \multirow[b]{2}{*}{ Bovinos } & \\
\hline & & & $\begin{array}{c}\text { Produtor } \\
(\%)\end{array}$ & $\begin{array}{l}\text { Tamanho } \\
\text { médio }\end{array}$ & & & & \\
\hline \multirow{5}{*}{$\mathrm{Z1}$} & Passa Vinte & $\operatorname{xxxx}$ & $\mathrm{x}$ & $\mathrm{xxxx}$ & $\mathrm{x}$ & $\mathrm{xxx}$ & $\mathrm{XX}$ & $\mathrm{xxx}$ \\
\hline & Tigre & $\mathrm{xxx}$ & $\mathrm{x}$ & $\mathrm{X}$ & $\mathrm{xx}$ & $\operatorname{xxxx}$ & $\mathrm{xx}$ & $\mathrm{xxx}$ \\
\hline & João XXIII & $\operatorname{xxxx}$ & $\mathrm{x}$ & $\mathrm{x}$ & $\mathrm{x}$ & $\operatorname{xxx}$ & $\mathrm{x}$ & $\mathrm{xx}$ \\
\hline & Tunas & $\operatorname{xxxx}$ & $\mathrm{x}$ & $\mathrm{xx}$ & $\mathrm{x}$ & $\mathrm{xxx}$ & $\mathrm{x}$ & $\mathrm{xxx}$ \\
\hline & Ouro Fino & $\operatorname{xxxx}$ & $\mathrm{x}$ & $\mathrm{xx}$ & $\mathrm{xxx}$ & $\operatorname{xxxx}$ & $\operatorname{xxxx}$ & $\mathrm{xxx}$ \\
\hline \multirow{4}{*}{$\mathrm{Z} 2$} & Antinha & $\mathrm{x}$ & $\operatorname{xxxx}$ & $\mathrm{x}$ & $\mathrm{xx}$ & $\mathrm{xx}$ & $\mathrm{x}$ & $\mathrm{x}$ \\
\hline & Campo Novo & $\mathrm{xx}$ & $\mathrm{Xxx}$ & $\mathrm{xxx}$ & $\mathrm{xx}$ & $\mathrm{x} \mathrm{XX}$ & $\mathrm{x}$ & $\mathrm{xx}$ \\
\hline & CabeçaD'Anta & $\mathrm{xx}$ & $\mathrm{xx}$ & $\mathrm{xxx}$ & $\mathrm{xx}$ & $\mathrm{xx}$ & $\mathrm{xxx}$ & $\mathrm{x}$ \\
\hline & Marrecas & $\mathrm{xx}$ & $\mathrm{xxx}$ & $\mathrm{X}$ & $\mathrm{x}$ & $\operatorname{xxxx}$ & $\operatorname{xxxx}$ & $\mathrm{x}$ \\
\hline \multirow{3}{*}{$\mathrm{Z} 3$} & Rio Abaixo & $\mathrm{xxx}$ & $\operatorname{xxxx}$ & $\operatorname{xxxx}$ & $\mathrm{x}$ & $\mathrm{xxx}$ & $\operatorname{xxxx}$ & $\mathrm{xx}$ \\
\hline & Palmital & $\mathrm{xxx}$ & $\mathrm{xxx}$ & $\operatorname{xxxx}$ & $\mathrm{xx}$ & $\operatorname{xxxx}$ & $\mathrm{xxx}$ & $\mathrm{x}$ \\
\hline & Pau de Sangue & $\mathrm{xxx}$ & $\mathrm{xxx}$ & $\operatorname{xxxx}$ & $\mathrm{xx}$ & $\operatorname{xxxx}$ & $\mathrm{xx}$ & $\mathrm{x}$ \\
\hline \multirow{4}{*}{$\mathrm{Z} 4$} & Cachoeirinha & $\mathrm{x}$ & $\mathrm{x}$ & $\mathrm{x}$ & $\mathrm{xxx}$ & $\mathrm{XX}$ & $\mathrm{x}$ & $\mathrm{xxxx}$ \\
\hline & Aterradinho & $\mathrm{x}$ & $\mathrm{xx}$ & $\mathrm{xxx}$ & $\mathrm{xxx}$ & $\mathrm{xxx}$ & $\mathrm{xx}$ & $\mathrm{xx}$ \\
\hline & Olaria & $\mathrm{x}$ & $\operatorname{xxxx}$ & $\mathrm{x}$ & $\operatorname{xxxx}$ & $\mathrm{X}$ & $\mathrm{xx}$ & $\mathrm{x}$ \\
\hline & Salto & $\mathrm{xx}$ & $\operatorname{xxxx}$ & $\mathrm{xxx}$ & $\operatorname{xxxx}$ & $\mathrm{xxx}$ & $\mathrm{xxx}$ & $\mathrm{x}$ \\
\hline
\end{tabular}

1- Tamanho médio imóvel= X: micro (até 4 ha); XX: pequena (de 4 a 15 ha); XXX: média (de 15 a 32 ha); XXXX: grande (acima de 32 ha).2- Intensidade de uso das terras= X: uso mínimo, subsistência; XX: uso regular, pouca diversificação; XXX: bom uso, diversificação regular; XXXX: uso intensivo, diversificação intensa.3- Trabalho (disponibilidade e intensidade)= X: baixa; XX: regular; XXX: boa.

ZONA 4 - comunidades de Cachoeirinha, Salto, Olaria e Aterradinho.

Predominam as micropropriedades, com áreas inferiores a 5 ha, apresentando área trabalhada média superior à área total das demais zonas agroeconômicas. Os agricultores cultivam terrenos de terceiros, em face da inviabilidade de acesso à terra, decorrente da escassez de novas áreas e de capital. A bracatinga tem ocorrência marcante, especialmente na comunidade do Salto. Existem muitos pequenos produtores especializados em olericultura, tendo a produção de milho, feijão e suínos como atividade complementar. Na área limítrofe com o município de Colombo, pontualmente encontram-se os melhores solos da região, com declividade média variável entre 10 e $20 \%$.

\section{Perfil do produtor de bracatinga}

A população rural está em fase de envelhecimento global, em razão da emigração dos jovens para Curitiba ou outras zonas rurais mais dinâmicas. Dados do IBGE (2000) indicam que aproximadamente $45 \%$ da população ativa dedicava-se às atividades agropecuárias, contra $59 \%$ em 1980 e $71 \%$ em 1970. O grau de instrução da população é baixo, estimada em 35\%, sendo inferior à média regional, embora tenha ocorrido uma gradual redução da taxa de analfabetismo da população rural.

A população é composta principalmente por descendentes de europeus (especialmente de italianos, além de poloneses e alemães em menor proporção), que chegaram no início do século XX. Em geral, a população rural da área de estudo caracteriza-se por sua estagnação numérica, associada a uma forte miscigenação cultural e étnica. Verificou-se que a idade média dos proprietários rurais é bastante avançada, com 58\% deles apresentando mais de 50 anos de idade, fato preocupante para garantir uma manutenção de silvicultura em bases vigorosas, típica para os produtores de bracatinga. 
Dos produtores de bracatinga entrevistados, apenas $42 \%$ possuem idade inferior a 50 anos, sendo quase todos herdeiros das propriedades e mais suscetíveis a mudanças no processo produtivo. Por outro lado, a maioria dos filhos já se retirou do meio rural, mantendo residência nas cidades, fato que explica o fenômeno do êxodo ocorrido, frente às poucas oportunidades existentes para o pagamento da mão de obra com base no referencial urbano.

\section{Área média de corte anual de bracatinga}

Os indicadores demonstram que o processo produtivo de bracatinga mantém uma relativa linearidade entre a área de corte anual e a área de regeneração de bracatingais. A paisagem regional forma um mosaico de bracatingais com idades sequenciais do crescimento das árvores, similar a um tabuleiro de xadrez.

A média de corte anual de bracatingais observada nas propriedades, identificada por estrato fundiário, é inferior a 20 hectares, com predomínio de talhões entre 2 a 5 hectares de produção e corte, confirmando os resultados do trabalho realizado por Dossa et al. (2004).

A área passível de corte observada em 2006, com idade superior a 7 anos, era de $37 \%$, tendo havido um desajuste da área total de corte anual em decorrência das restrições ambientais estabelecidas pelo IAP, em face da Lei $n^{\circ} 11.428$, de 22/12/2006, e da Portaria $n^{\circ} 108$, de 13/07/2007, as quais priorizam a conservação da vegetação.

\section{Remuneração mensal do produtor de bracatinga}

O cultivo de bracatingais constitui alternativa de renda para o produtor rural, desenvolvido normalmente numa área de corte anual que não ultrapassa os 20 hectares, corroborando as observações dos trabalhos realizados por Laurent e Mendonça (1989).

A permanência dos produtores no cultivo de bracatinga pode ser compreendida a partir da formação da renda total da propriedade. Em confirmação aos dados de Dossa et al. (2004), verificou-se que a renda média total nas propriedades é de $\mathrm{R} \$ 6.649,00$, representando $\mathrm{R} \$ 554,00$ por mês ou $\mathrm{R} \$ 369,00$ por pessoa envolvida, enquanto em grandes propriedades esse valor aumenta para $\mathrm{R} \$ 768,61$ por pessoa/mês.

Quando uma família possui um de seus membros aposentado, com pensão governamental, torna a bracatinga uma atividade competitiva com a renda média urbana para pessoas de baixa qualificação profissional. Outrossim, a produção de bracatinga não exige trabalho durante o desenvolvimento das árvores, fato que explica a permanência de produtores de bracatinga no meio rural até uma idade avançada.

Por outro lado, todos os produtores com áreas inferiores a 100 hectares apresentam problemas de renda, pois cada propriedade com 1,5 membros da família trabalhando com a bracatinga apresenta uma média de remuneração de $\mathrm{R} \$ 470,00$ mensais. Como as áreas médias de corte de bracatinga são de apenas 6,3 hectares, geram uma renda média anual de $\mathrm{R} \$ 8.592,50$, ou seja, $\mathrm{R} \$ 716,00$ por mês na família por propriedade.

No meio urbano da Região Metropolitana de Curitiba, o trabalhador recebe um salário mínimo atual de $\mathrm{R} \$ 510,00$, associado ao décimo terceiro salário, férias e FGTS, ou seja, recursos financeiros superiores ao valor dos recursos provenientes da produção e comercialização de madeira de bracatinga. A situação fica mais desfavorável quando se analisa o custo da oportunidade da terra, benfeitorias, máquinas e equipamentos empregados na produção de bracatinga, os quais não foram considerados neste estudo.

\section{Mosaico dos bracatingais}

No levantamento dos 257imóveis rurais com 2.958 hectares de plantios, verificou-se uma área média de 11,30 hectares de bracatinga, distribuídas em 4 agrupamentos de idades diferenciadas, ou seja:

- $15 \%$ para plantios com até 2 anos (plantação de bracatinga que permite a execução das técnicas de limpeza de sub-bosque, raleio, adubação e desramagem);

- $25 \%$ para plantios entre 3 e 5 anos de idade (bracatingal que permite eventual execução de raleio e limpeza de sub-bosque, além da técnica da desramagem);

- $\quad 23 \%$ para plantios entre 5 e 7 anos (idade sem condições de manejo silvicultural); 
- $\quad 37 \%$ para plantios com idade superior a 7 anos (madeira potencial para indústria, mediante seleção de toras acima de 20 centímetros de diâmetro, efetuada durante o corte e empilhamento).

Observou-se que a produtividade média atual dos bracatingais, num ciclo de 7 anos, é relativamente baixa, variando entre 150 e $200 \mathrm{~m}^{3} /$ ha de lenha. Dentre as causas, destacou-se a ausência de melhoramento genético para disponibilizar sementes qualificadas para a produção de madeira de uso industrial e por tipo de sítios de produção.

A renovação dos bracatingais é efetuada mediante a queima dos resíduos da colheita de madeira para limpeza do terreno, seguida da regeneração do banco de sementes. Ocorre a quebra de dormência das sementes, com desenvolvimento inicial da bracatinga, associado ao plantio de milho-feijão, corroborando Laurent e Mendonça (1989). Verificou-se que a germinação média corresponde a uma densidade variável entre 40 mil e 100 mil plantas no primeiro ano, ficando ao redor de 25 mil plantas por hectare ao final do segundo ano.

O plantio de mudas de bracatinga, tanto em terreno preparado (aração e gradagem) como em terreno não preparado, apenas com coveamento, constitui prática raramente usada pelos produtores, apesar de recomendações de Mazuchowski e Laurent (1993) e Carpanezzi (1994). O espaçamento mínimo utilizado para plantio por sementes é de $1 \mathrm{~m}$ x $1 \mathrm{~m}$ entre plantas, enquanto que para plantios por mudas usa-se $4 \mathrm{~m}^{2}$ a $5 \mathrm{~m}^{2}$ por planta, de conformidade com as orientações da EMBRAPA (1988) e Carpanezzi (1994). Espaçamentos maiores na fase inicial não são usados, em face da dominância de espécies herbáceas invasoras.

A adubação nas covas e a supressão eficaz da competição por gramíneas e outras plantas não são técnicas silviculturais adotadas, principalmente devido ao baixo valor pago pela madeira, corroborando os dados de EMBRAPA (1988) e LAURENT et al. (1990). No cultivo de bracatinga por regeneração natural, sem etapa agrícola inicial, nenhuma capina e raleio são realizados, sendo necessário efetuar a limpeza do sub-bosque, mediante duas a três capinas nos primeiros cinco meses, com raleio parcial do número de plantas.

O sistema de corte usual das árvores passou da foice e machado para foice e motosserra, procurando-se cortar os troncos e galhos em peças de 1,0 metro de comprimento. Com apoio de um cavalo ou boi e de uma "zorra", atualmente substituídos por trator com carreta e/ou caminhonete, transporta-se o produto até a beira do carreador, empilha-se a madeira cortada e aguarda-se a venda e seu transporte final.

Ao final do processo de produção, a madeira de bracatinga apresenta características físicas básicas classificadas como moderadamente pesada, resistência mecânica média, difícil de cortar mas fácil de aplainar ou lixar, possuindo problemas na sua secagem que determinam a necessidade de usar programas suaves, devido à sua alta propensão ao colapso (KLITZKE, 2006). Por essa razão, a secagem deve ser conduzida em baixa temperatura.

\section{Restrições ambientais para a silvicultura da bracatinga}

O documento Informação de Corte com Declaração de Origem para Manejo Florestal da Bracatinga, Formulário D, instituído pela Resolução no 023, de 08/06/2004, da SEMA, é o documento que instruiu os procedimentos na propriedade, englobando as atividades silviculturais de corte raso, raleio e queima controlada no bracatingal, para regeneração do dossel. Essa concessão é fornecida pelo IAP, condicionada à observância da homogeneidade da formação florestal requerida para o corte, ou seja, mediante alta concentração de bracatinga, correspondente ao mínimo de $70 \%$ das árvores entre as espécies arbóreas existentes no povoamento.

Dessa forma, após a solicitação requerida pelo proprietário do bracatingal, com pagamento da taxa ambiental e da taxa de vistoria correspondentes (valor variável de acordo com a distância percorrida pelo fiscal do IAP), ocorre a vistoria da área para viabilizar a emissão da autorização de corte do bracatingal. Em termos práticos, verifica-se longa morosidade no processo de obtenção da autorização de corte da bracatinga, uma verdadeira via crucis, com diversos casos mencionados pelos produtores superando a um ano de espera. As causas básicas estão nas frequentes alterações nos processos de encaminhamento adotados pelo órgão ambiental, privilegiando o enfoque ambientalista em prejuízo total do aspecto econômico da agricultura familiar, sem oferecer alternativas de sobrevivência, aliado à carência de recursos operacionais do IAP. 
Em paralelo, através do Decreto $\mathrm{n}^{\circ} 3.320$, de 12/07/2004, o estado do Paraná determinou a obrigatoriedade de regularização prévia do SISLEG pelo proprietário rural, para ser beneficiário de processos que requeiram procedimentos junto ao IAP e programas governamentais. Atualmente, nenhuma autorização de corte é liberada pelo IAP caso o produtor de bracatinga não comprove previamente a elaboração do projeto do SISLEG, devidamente registrado na escritura do imóvel rural. Essa regra governamental é apontada pelos produtores como um dos principais gargalos da cadeia produtiva da bracatinga.

Adicionalmente, a Resolução Conjunta IBAMA/SEMA/IAP $\mathrm{n}^{\circ}$ 01, de 01/06/2007, definiu o manejo das plantações de bracatinga pura para garantir a perpetuidade da espécie, ou seja, após feito o corte das árvores, a mesma área deve ser conduzida para a regeneração e produção num novo ciclo da espécie, desde que disponham de um mínimo de $80 \%$ dos indivíduos da espécie florestal Mimosa scabrella Bentham. Essa Resolução estabeleceu também instruções ao processo de licenciamento do corte das árvores.

Através da Lei $\mathrm{n}^{\mathrm{o}} 11.428$, de 22/12/2006, consideram-se como integrantes do Bioma Mata Attântica as formações florestais nativas e ecossistemas associados estabelecidos pela Floresta Ombrófila Densa, pela Floresta Ombrófila Mista, também denominada de Mata com Araucárias (onde estão os bracatingais), pela Floresta Ombrófila Aberta, pela Floresta Estacional Semidecidual e pela Floresta Estacional Decidual, bem como pelos manguezais, vegetações de restingas, campos de altitude, brejos interioranos e encraves florestais do Nordeste.

Somente os remanescentes de vegetação nativa no estágio primário e nos estágios secundário inicial, médio e avançado de regeneração têm seu uso e conservação regulados por essa Lei. Nela, entende-se como bracatingal não manejado aquele que tenha ocorrência de mais de $20 \%$ de outras espécies arbóreas no dossel.

Por outro lado, considera-se como pequeno produtor rural aquele que, residindo na zona rural, detenha a posse de gleba rural não superior a 50 hectares, explorando-a mediante o trabalho pessoal e de sua família, admitida a ajuda eventual de terceiros, bem como as posses coletivas de terra, considerandose a fração individual não superior a 50 hectares, cuja renda bruta seja proveniente de atividades ou usos agrícolas, pecuários ou silviculturais ou do extrativismo rural em $80 \%$ no mínimo.

Contudo, continua a prevalecer o rigor unilateral na aplicação da legislação ambiental, especialmente pelo IAP, Força Verde da Polícia Militar do Paraná e Promotoria do Meio Ambiente. As posturas são bastante restritivas ao manejo silvicultural e ao corte da bracatinga, aliadas à exigência para atendimento de procedimentos excessivamente burocratizados, mas sem oferecer alternativas econômicas concretas ao agricultor.

Complementarmente, através da Portaria IAP no 108, de 13/06/2007, foram estabelecidos novos procedimentos administrativos para o manejo da bracatinga no estado do Paraná, com enquadramento diferenciado dos bracatingais em dois grupos distintos de imóveis rurais - propriedades de até 50 hectares para pequeno produtor e propriedades superiores a 50 hectares para as categorias de médio e grande produtor.

\section{Penalização da bracatinga para produção de água metropolitana}

A Região Metropolitana de Curitiba é caracterizada por grande número de áreas de mananciais, com nascentes de importantes rios, formadas pelas várzeas do Rio Iguaçu e pelas APAs do Passaúna e do Iraí, além de ser relevante reserva de água subterrânea formada pelo Aquífero Karst.

Em contraste, atualmente um terço da população paranaense vive em menos de $10 \%$ do território do estado, o que resulta na contaminação dos cursos d'água, evidenciando a falta de consciência da população e a inércia do estado, aliadas ao consumo crescente da mesma água.

Enquanto isso, os produtores de bracatinga sofrem com a postergação das autorizações de manejo das áreas de plantio da bracatinga pelos órgãos responsáveis. Como se fossem os culpados dos desmandos e insensibilidade da população urbana, os bracatingais puros tendem a se tornarem mistos, pela demora da emissão das autorizações de corte correspondentes.

A legislação ambiental apresenta forte caráter proibitivo e restritivo ao produtor de bracatinga, embora não tenha alcançado os resultados que alguns ainda esperam. É imperioso estimular medidas de incremento da conservação e preservação da qualidade da água destinada ao meio urbano, contudo devem 
ser ajustadas medidas que deixem de penalizar unilateralmente a atividade florestal cíclica e secular na mesma região.

\section{Organização da produção de bracatinga}

Observou-se a falta de apoio das lideranças e entidades governamentais, dos municípios e do estado, para incrementar parcerias dos produtores de bracatinga com as indústrias consumidoras de madeira.

O uso histórico da madeira voltado para a produção de energia e a falta de preço alternativo para madeira manejada, em bases favoráveis para qualidade e tecnologia adotada pelo produtor, constituem o grande entrave e desmotivação para parcerias. Como exemplo comparativo, verificou-se que uma árvore em pé valia $R \$ 15,00 \mathrm{o} \mathrm{m}^{3}$, aumentando para $R \$ 20,00$ se colocada cortada e empilhada em peças de um metro no carreador, podendo atingir valores entre $R \$ 25,00$ e $R \$ 30,00 \mathrm{o} \mathrm{m}^{3}$ se colocada no pátio da empresa consumidora. Por outro lado, o valor da madeira de bracatinga manejada e destinada para a movelaria facilmente chega a valores de 10 a 20 vezes superiores aos do mercado de lenha.

As prioridades identificadas para incremento da produção-produtividade estão centradas na introdução de técnicas silviculturais, especialmente de plantio por mudas, raleio de plantas nas áreas de regeneração, desrama das árvores para qualificação das toras e emprego do lodo de esgoto alcalinizado como fertilização. Verifica-se uma baixa atuação da assistência técnica, em especial do Instituto EMATER, bem como um apoio mínimo da Companhia de Saneamento do Paraná (SANEPAR) junto aos produtores de bracatinga, apesar da oferta de lodo de esgoto alcalinizado sem ônus para a Agricultura Familiar, com transporte até o imóvel rural, visando fertilização dos solos florestais.

A existência de viveiros florestais nas sedes municipais não chega a ser um apoio na produção de mudas, devido ao desinteresse pelo plantio por mudas e a qualidade das mudas ofertadas, geralmente de baixo padrão silvicultural. Após o corte das árvores, realiza-se negociação individual para comercialização da madeira, normalmente através de compradores intermediários ao consumidor, sendo destinado ao uso energético.

De uma forma marcante, os compradores intermediários existentes nos municípios são representados por um grupo pequeno e exclusivo de pessoas dotadas de recursos financeiros e caminhões de transporte da madeira. Normalmente têm vínculos familiares e/ou de vizinhança históricos, além do domínio da informação junto aos centros compradores da Região Metropolitana de Curitiba. A comercialização diretamente com o consumidor industrial e comercial é feita de forma direta, obedecendo a um cronograma de entrega. Por sua vez, a madeira comercializada por intermediários do mercado da madeira para consumidor residencial efetua um processamento para peças pequenas, gerando agregação de valor.

Eventuais vendas de toras de bracatinga para fins industriais, especialmente para confecção de mobiliário e/ou peças de móveis, além de assoalhos e laminados, são realizadas por produtores com áreas maiores de bracatingais. As indústrias filiadas ao SINDIMOV (Sindicato das Indústrias Moveleiras da Região Metropolitana de Curitiba) representam o segmento empresarial com demandas relevantes por madeira de bracatinga. Verificou-se que o dimensionamento estabelecido pelos consumidores industriais apresenta muita diferenciação nas bitolas das toras de bracatinga, de acordo com a destinação da madeira. A aquisição das toras de madeira é feita em comprimentos de $1,00 \mathrm{~m}, 1,25 \mathrm{~m}$ e 2,50 metros, com diâmetro mínimo de 8 centímetros, descascadas ou não. O descascamento das toras requerido por algumas indústrias implica utilização de equipamentos atualmente não disponíveis para essa espécie florestal. Alia-se a isso a necessidade de mudança de procedimentos silviculturais pelo produtor e inclusão do descascamento no custo de produção da madeira.

Em 2008, foi instalada em Bocaiuva do Sul uma indústria de peletização da madeira de bracatinga - Indústria GRYM Bioenergia -, visando suprir necessidades energéticas de indústrias de diversos segmentos do Paraná e outros estados, além do mercado internacional, especialmente europeu. Representa um avanço organizacional para a cultura da bracatinga nas propriedades rurais.

\section{CONCLUSÕES}

Os indicadores do estudo apontam para a triste realidade de que a cadeia produtiva da bracatinga será inviável no curto prazo, de forma econômica, caso seja mantida a atual intervenção do serviço de 
fiscalização com rígido enfoque ambientalista, aliado ao desconhecimento da realidade rural na atual ótica da sociedade urbana.

Diante das manifestações expressas pelos produtores de bracatinga, a conclusão do estudo está alicerçada especialmente nos seguintes fatos:

- Falta de percepção da realidade social pelos governantes, lideranças e sociedade urbana, que consideram o produtor de bracatinga um ser marginal, que deve ser penalizado, apesar de possuir uma área média de bracatinga de apenas 11,30 hectares para corte escalonado (o produtor atrapalha).

- Falta titulação das terras rurais com definição da posse efetiva dos imóveis e permissão de uso pelos proprietários, para viabilizar o acesso a concessões creditícias e parcerias com as indústrias.

- Postura da fiscalização ambiental bastante incompatível com as propostas de desenvolvimento regional rural, exigindo urgente modificação de procedimentos e normativas legais, para viabilizar geração de renda e emprego associada à adoção de tecnologia na bracatinga (a prioridade é urbana).

- Ausência de parcerias entre indústrias florestais e produtores de bracatinga, para garantir o fornecimento contínuo de madeira de qualidade industrial, associado à utilização de técnicas silviculturais de qualificação da madeira e estabelecimento de preços estimulantes. A remuneração da lenha é insuficiente para manutenção da família rural em pequenas propriedades.

- A maioria dos produtores encontra-se na faixa etária superior a 50 anos e está aposentada, enquanto seus filhos não trabalham ou deixaram de trabalhar na propriedade, embora 50\% deles apresentem sua fonte de renda principal na venda da madeira de bracatinga. Adicionalmente, verifica-se escassez de mão de obra para desenvolver atividades no meio rural.

- Falta viabilizar mecanismos financeiros alternativos para o produtor, visando o levantamento das áreas de preservação permanente (APP e Reserva Legal) e registro nas escrituras dos imóveis rurais, frente à postura policialesca do estado e à incapacidade financeira dos produtores, descapitalizados e inviabilizados de atuar economicamente com bracatinga.

- Desmotivação dos produtores de bracatinga, em face dos impedimentos da burocracia para obtenção da autorização de corte, da falta de priorização municipal da atividade florestal nos planos das prefeituras municipais e da insuficiência de assistência técnica às propriedades rurais.

\section{REFERÊNCIAS}

BHERING, S. B.; SANTOS, H. G. Mapa de solos do estado do Paraná - legenda atualizada. Rio de Janeiro: EMBRAPA Florestas \& EMBRAPA Solos \& IAPAR, 2008. 74 p.

CARPANEZZI, A. A.; CARPANEZZI, O. T. B.; BAGGIO, A. J. Manejo de Bracatingais. In: Anais da Oficina sobre Bracatinga no Vale da Ribeira / Guaraqueçaba. Agência de Desenvolvimento da Mesorregião do Vale da Ribeira / EMATER-Paraná / EMBRAPA Florestas. Curitiba, 2004. 60 p.

CARPANEZZI, O. T. B. Produtividade florestal e agrícola em sistemas de cultivo de bracatinga (Mimosa scabrella Bentham) em Bocaiuva do Sul, Região Metropolitana de Curitiba-PR. Piracicaba: ESALQ, 1994. 77 p. Dissertação de Mestrado.

CARVALHO, P. E. R. Espécies florestais brasileiras: recomendações silviculturais, potencialidades e uso da madeira. EMBRAPA Florestas. Colombo: EMBRAPA-CNPF. Brasília: EMBRAPA - SPI, 1994. $640 \mathrm{p}$.

DOSSA, D.; MONTOYA, L. J.; MACHADO, A. M. B. Cenário socioeconômico da Produção de Bracatinga. In: Anais da Oficina sobre Bracatinga no Vale da Ribeira / Guaraqueçaba. Agência de Desenvolvimento da Mesorregião do Vale da Ribeira / EMATER-Paraná / EMBRAPA Florestas. Curitiba. 2004. 60 p.

EMPRESA BRASILEIRA DE PESQUISA AGROPECUÁRIA (EMBRAPA). Centro Nacional de Pesquisa de Florestas. Manual Técnico de Bracatinga (Mimosa scabrella Benth.). EMBRAPA-CNPF. Documentos, 20. Colombo, 1988. 70 p. 
EMPRESA BRASILEIRA DE PESQUISA AGROPECUÁRIA (EMBRAPA). Levantamento de Reconhecimento de Solos do Estado do Paraná. Serviço Nacional de Levantamento e Conservação de Solos, EMBRAPA-SNLCS. Rio de Janeiro. Série Documentos n.96. 2007.

HOEHNE, F. C. A Bracaatinga ou Abaracaatinga. Secretaria da Agricultura, Industria e Commercio do Estado de São Paulo. São Paulo, 1930. 50 p.

INSTITUTO AGRONÔMICO DO PARANÁ (IAPAR). Cartas Climáticas do Estado do Paraná: 1994. Londrina, 1994. (IAPAR, Documentos, 18).

INSTITUTO BRASILEIRO DE GEOGRAFIA E ESTATÍSTICA (IBGE). Censo Agropecuário. Rio de Janeiro: IBGE: Censo Agropecuário - 1995.

KLITZKE, R. J. Desenvolvimento de programa de secagem para madeira de Mimosa scabrella (bracatinga) com 26 mm de espessura. UFPR - FUPEF (Convênio Agência de Desenvolvimento da Mesorregião do Vale do Ribeira/Guaraqueçaba). Curitiba, 2006.

LAURENT, J. M. E. Sistema agroflorestal da bracatinga na Região Metropolitana de Curitiba: Contexto socioeconômico. Curitiba: EMATER-PR, 1990. 50 p. il. (Projeto FAO-GCP/BRA/025/FRA. Série Estudos Florestais, 3).

LAURENT, J. M. E.; MENDONÇA, W. R. Abastecimento de lenha às indústrias da Região Metropolitana de Curitiba - Norte. Curitiba: EMATER-PR, 1989. 40 p. il. (Projeto FAOGCP/BRA/025/FRA. Série Estudos Florestais, 2).

MAZUCHOWSKI, J. Z. Guia para pesquisa de mercado de produtos florestais. Câmara Setorial da Erva-Mate do Estado do Paraná (Convênio MCT/CNPq/SEAB/CITPAR/EMATER-Paraná/APIMATE). Curitiba. 2001. 90 p. il. (Projeto PADCT III - Programa de Apoio ao Desenvolvimento Científico e Tecnológico).

Organização da reposição florestal. Curitiba: EMATER-PR, 1990. 126 p. il. (Projeto FAOGCP/BRA/025/FRA. Série Subsídios Florestais, 2).

MAZUCHOWSKI, J. Z.; BECKER, J. C. Relatório de atividades do Projeto Unidades Rurais de Desenvolvimento Integrado 2004 a 2006. Instituto EMATER e Agência de Desenvolvimento da Mesorregião Vale do Ribeira / Guaraqueçaba. Curitiba, 2006. 150 p.

MAZUCHOWSKI, J. Z.; LAURENT, J. M. E. Melhoramento da produção energética e alimentícia na agricultura tradicional do estado do Paraná (Projeto Bracatinga) - Conclusões e Recomendações. EMATER-Paraná e FAO (Projeto GCP/BRA/025/FRA). Bocaiuva do Sul, 1993.128 p.

MAZUCHOWSKI, J. Z.; da SILVA, V. P.; BECKER, J. C. Anais da Oficina sobre Bracatinga no Vale da Ribeira / Guaraqueçaba. Agência de Desenvolvimento da Mesorregião do Vale da Ribeira / EMATER-Paraná / EMBRAPA Florestas. Curitiba. 2004. 60 p.

VALE DO RIBEIRA - Fórum Mesorregional de Desenvolvimento - Câmara de Cultivos Florestais. Dossiê da Bracatinga- Impedimentos para o Desenvolvimento da Cadeia Produtiva da Bracatinga. Agência de Desenvolvimento da Mesorregião do Vale do Ribeira / Guaraqueçaba. Curitiba, 2007. 8 p. 